\title{
The Implication of N-Acetylglucosaminyl- transferase V Expression in Gastric Cancer
}

\author{
Hai Tian ${ }^{\text {a }}$ Eiji Miyoshi $^{\text {b Naomasa Kawaguchi }}{ }^{\mathrm{a}}$ Mohammed Shaker $^{\mathrm{a}}$ \\ ${\text { Yasuhiro } \text { Ito }^{a} \text { Naoyuki Taniguchi }}^{c}$ Masahiko Tsujimoto ${ }^{d}$ Nariaki Matsuura $^{a}$ \\ Departments of a Molecular Pathology and ${ }^{\mathrm{b}}$ Biochemistry, Graduate School of Medicine and Health Science, and \\ 'Department of Disease Glycomics, Research Institute for Microbial Diseases, Center for Advanced Science and \\ Innovation, Osaka University, Suita, and d Department of Pathology, Osaka Police Hospital, Osaka, Japan
}

\section{Key Words}

Gastric cancer $\cdot$ GnT-V • Immunohistochemistry •

Metastasis · Prognosis, gastric cancer

\begin{abstract}
Objective: $\mathrm{N}$-acetylglucosaminyltransferase $\mathrm{V}(\mathrm{GnT}-\mathrm{V})$ is a key enzyme that catalyzes $\beta_{1-6}$ branching of $\mathrm{N}$-acetylglucosamine on $\mathrm{N}$-glycan of cell proteins, some of which are linked with metastasis. GnT-V expression was studied immunohistochemically in gastric cancer to compare clinicopathological parameters and evaluate the role of GnT-V in the prognosis of gastric cancer. Methods: Immunohistochemistry was carried out to detect GnT-V expression in 50 advanced gastric cancer tissues where the depth of invasion exceeded the subserosa, and the relationship between GnT-V expression and various clinicopathological factors, including survival, was analyzed. Results: GnT-V was expressed in 23 (46\%) gastric cancer tissues. GnT-V expression was significantly correlated with lymph node metastases, peritoneal dissemination and liver metastases, respectively $(p=0.005, p=0.013$ and $p=0.023$ ). Patients with GnT-V-positive gastric cancer had a significantly shorter survival than those without GnT-V expression (5-year survival rate: 31.2 and $54.4 \%$, respectively; $\mathrm{p}=0.045)$. Conclusion: GnT-V expression is correlated with a poor prognosis in gastric cancer patients due to metastases.

Copyright $\odot 2008$ S. Karger AG, Basel
\end{abstract}

\section{Introduction}

Gastric cancer is the second most common cause of cancer-related mortality worldwide and its incidence is raised in Japan, China and South America [1]. Although most patients with early gastric cancer can be cured with minimally invasive treatment, the prognosis of patients with advanced gastric cancer remains poor since many patients develop a recurrence with peritoneal dissemination or liver metastases [2]. However, since factors which may contribute to metastasis of gastric cancer have been elucidated [3, 4], we aimed to look for a marker which is able to predict the metastatic potential of advanced gastric cancer and to identify patients with a poor prognosis who are prone to recurrence of gastric cancer.

There are two kinds of glycans of glycoprotein in the human tissue, $\mathrm{O}$-glycans and $\mathrm{N}$-glycans. Both O-glycans and $\mathrm{N}$-glycans are widely distributed on the cell surface and secreted glycoprotein, whose structural changes are frequently observed in development, carcinogenesis and malignant transformation [5-7]. $\beta_{1-6}$ GlcNAc branching on $\mathrm{N}$-glycan is synthesized by $\mathrm{N}$-acetylglucosaminyltransferase (GnT-V), a key enzyme in the processing of multiantennary $\mathrm{N}$-glycans during glycoprotein biosynthesis $[8,9]$. This enzyme transfers $\mathrm{N}$-acetylglucosamine from UDP-N-acetylglucosamine to 1-6 mannoside of asparagine-linked oligosaccharides [8]. During oncogene-

Prof. Nariaki Matsuura

Department of Molecular Pathology

Graduate School of Medicine and Health Science, Osaka University

1-7 Yamada-oka, Suita, Osaka 565-0871 (Japan)

Tel. +81 66879 2591, Fax +81 66879 2595, E-Mail matsuura@sahs.med.osaka-u.ac.jp 
sis, the increase in GnT-V activity and its cell surface products results from increased transcription driven by activation of the Ras-Ets and protein kinase B signaling pathway [10-12]. Some studies have demonstrated that increased expression of GnT-V in breast and colorectal cancer correlates with distant metastases and a poor prognosis [13-15]. In contrast, it does not correlate with a poor prognosis in hepatoma and non-small cell lung cancer $[16,17]$. Hepatoma cells with high GnT-V expression, e.g. HuH7 and HepG2 cells, showed no metastasis in studies using athymic mice [18]. These results indicate the biological significance of GnT-V is apparently different for each type of cancer. It was also reported that gastric cancer cells in which the GnT-V gene was transduced overexpressed GnT-V; GnT-V transfectants injected into the abdominal cavity of nude mice resulted in increased metastasis formation 1 month later [19]. However, the relationship between GnT-V expression and metastasis and prognosis in human gastric cancer tissue is still unknown.

\section{Materials and Methods}

\section{Tissue Specimens and Patient Follow-Up}

Tissue specimens of gastric cancer were obtained from $50 \mathrm{pa}-$ tients (35 men and 15 women) who had undergone surgery at the Osaka Police Hospital in 1992-1996. In order to evaluate prognostic implications, more advanced cases with gastric cancer exceeding the subserosa were analyzed. There are 29 cases with subserosal invasion, 20 cases with penetration to the serosa without invasion of adjacent structures, and 1 case with invasion to adjacent structures. The patients were followed up in the outpatient clinic of the hospital for $>60$ months postoperatively. For immunohistochemical study, the tissues were fixed with $10 \%$ phosphate-buffered formalin, followed by preparation of paraffin-embedded blocks. In 50 patients, 8 cases metastasized to the peritoneum, 6 cases to the liver, 1 case to both peritoneum and liver, and 1 case metastasized to the spleen during the follow-up period after operation. The conventional clinicopathological parameters and TNM stage, followed by the criteria of the 5th International Union against Cancer TNM classification published in 1997 [20], were compared with GnT-V expression.

\section{Immunohistochemistry}

Antibody. For immunohistochemical evaluation, a mouse monoclonal antibody against recombinant human GnT-V, which was generated in the Department of Biochemistry, Osaka University Graduate School of Medicine [15], was prepared.

Method. Immunohistochemical studies for GnT-V were performed with the avidin-biotin complex method [21]. Briefly, tissue samples were prepared as $3-\mu \mathrm{m}$-thick sections from paraffinembedded specimens, followed by deparaffinization and blocking endogenous peroxidase activity with $0.3 \%$ hydrogen peroxide in methanol for $15 \mathrm{~min}$. After being washed in $0.01 \mathrm{mmol} / \mathrm{l}$ phos- phate-buffered saline (PBS) three times, $10 \%$ bovine serum was added for $30 \mathrm{~min}$ to block nonspecific binding at room temperature. A primary antibody (anti-GnT-V) was applied to sections at a concentration of $1: 100$ and incubated at $4^{\circ} \mathrm{C}$ overnight. After being washed 3 times in PBS, secondary antibody, biotinylated anti-mouse immunoglobulin (Amersham, London, UK), was applied for $30 \mathrm{~min}$ at a concentration of 1:200. After rinsing in PBS, peroxidase-conjugated streptavidin (at a concentration of 1:200; DAKO, Glostrup, Denmark) was incubated for $30 \mathrm{~min}$. The peroxidase reaction was carried out in $0.05 \mathrm{~mol} / \mathrm{l}$ Tris- $\mathrm{HCl}$ ( $\mathrm{pH} 7.6$ ) containing both $0.02 \% 3$,3-diaminobenzidine tetrahydrochloride and $0.03 \%$ hydrogen peroxide for $5 \mathrm{~min}$. The tissue sections were counterstained with hematoxylin.

Immunohistochemical Evaluation. The results for GnT-V expression in gastric cancer were divided into two groups according to the evaluation of the former studies: $+(>10 \%$ carcinoma cells expressed GnT-V) and $-(<10 \%$ carcinoma cells or no carcinoma cells expressed GnT-V) [16]. The staining sections were examined by two independent observers without prior knowledge of the clinical status of the patients.

\section{Statistical Analyses}

Values were expressed as means \pm SD. The $\chi^{2}$ test, Student's $t$ test and Fisher's exact probability method were applied to statistically analyze the association between GnT-V expression and all kinds of pathological parameters, e.g. differentiation, depth of invasion, venous invasion and lymph vessel invasion. $p<0.05$ was regarded as statistically significant. In order to analyze the survival rate of GnT-V-positive and GnT-V-negative patients, the logrank test was applied.

\section{Results}

\section{GnT-V Expression in Gastric Cancer}

Among 50 gastric cancers, GnT-V was expressed in both cancer cells and non-cancerous mucosal epithelial cells of 23 patients. The representative positive cases are shown in figure 1. The distribution of GnT-V-expressing cancer cells varied: in some cases, GnT-V-positive cancer cells were diffusely scattered, while GnT-V was heterogeneously disseminated in others. Though advanced gastric cancers penetrating the subserosa were examined, several cases developed multiple cancers including early cancers, and GnT-V was also detected in mucosal or submucosal gastric cancer. Thus GnT-V expression in gastric cancer cells was apparently not associated with the areas where cancer cells were present. In all GnT-V-positive cases, GnT-V was also expressed in normal gastric foveolar epithelium adjacent to gastric cancer, while GnT-V expression was lacking in intestinal metaplasia. The intensity of GnT-V expression gradually decreased with increasing distance from cancer cells, but we could not conclude whether these patterns were implicative or not since we did not test normal gastric tissues without can- 
Fig. 1. Immunohistochemical staining of GnT-V in gastric cancer tissue. a Adjacent normal mucosa. b Well-differentiated tubular adenocarcinoma. c Moderately differentiated tubular adenocarcinoma. d Poorly differentiated adenocarcinoma.
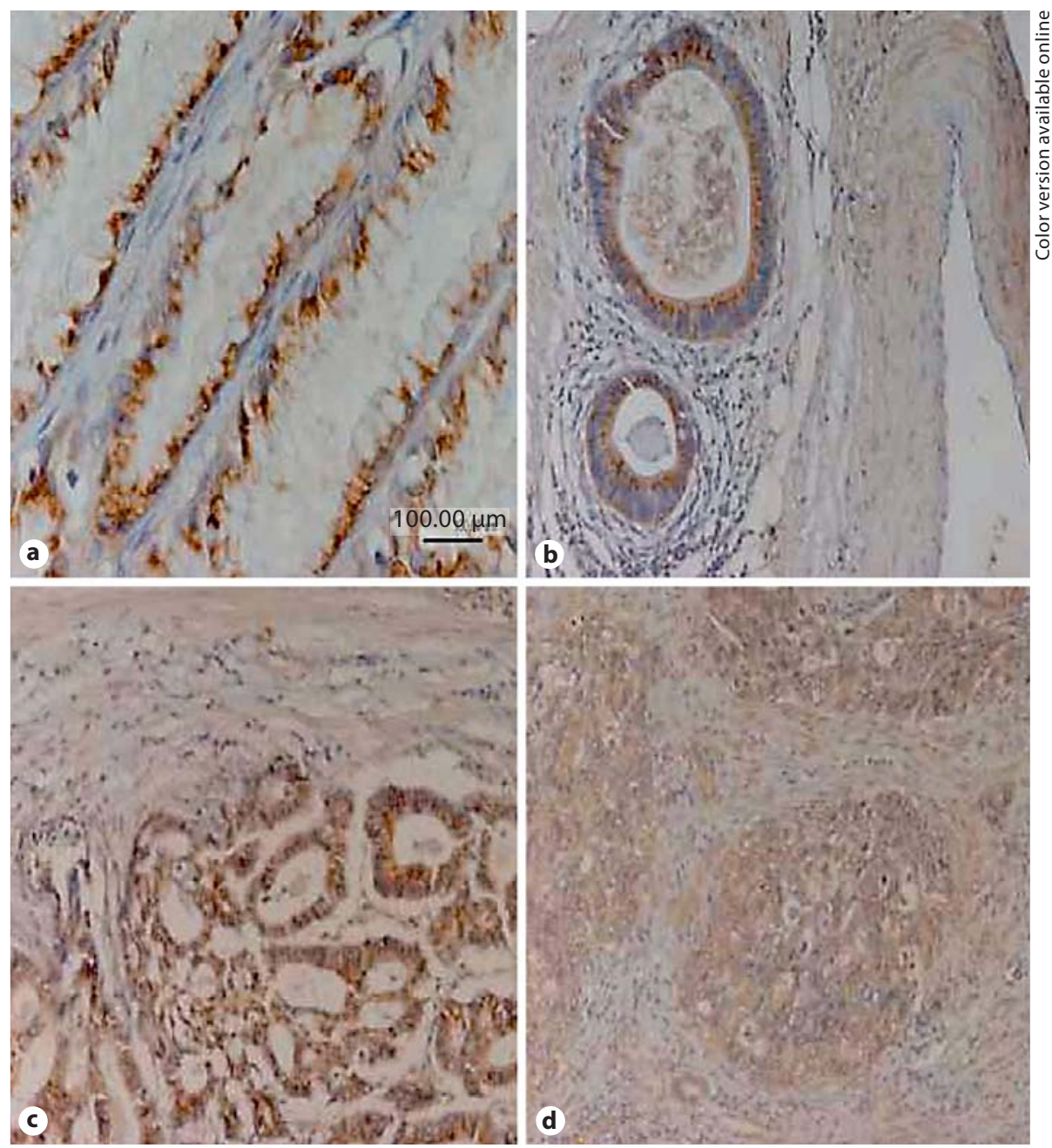

cer cells. Two cases demonstrated GnT-V expression in normal mucosa but not in cancer cells. In subcellular localization, GnT-V was diffusely scattered in the cytoplasm of most gastric cancer cells (fig. 1b-d). On the other hand, some gastric cancer cells showed GnT-V expression in the Golgi area as well as in normal epithelium (fig. 1a).

\section{Relationship between GnT-V Expression and \\ Clinical Parameters}

We analyzed the relationship between GnT-V expression and various clinicopathological features (table 1). There were significant associations between GnT-V expression and lymph node metastases, peritoneal dissemination and liver metastases, respectively $(\mathrm{p}=0.036, \mathrm{p}=$ 0.013 and $p=0.023$ ). In addition, GnT-V expression and curability were correlated $(\mathrm{p}=0.014)$. However, GnT-V expression was not associated with other parameters, e.g. sex, tumor size (maximal diameter), tumor location, histological differentiation, lymphatic invasion and vascular invasion.

\section{Relationship between GnT-V Expression and \\ TNM Staging}

We summarized the relationship between GnT-V expression and TNM staging factors in table 2 . There were significant correlations between $\mathrm{GnT}-\mathrm{V}$ expression and $\mathrm{N}$ factor (lymph node metastasis), $\mathrm{M}$ factor (distant metastasis) and TNM stage, respectively ( $\mathrm{p}=0.0054, \mathrm{p}=0.0018$ and $\mathrm{p}=0.0043$ ), but $\mathrm{T}$ factor (tumor depth) was not associated with GnT-V expression. These results are consistent with those for clinicopathological parameters. 
Table 1. GnT-V expression and clinicopathological parameters in gastric cancer patients

\begin{tabular}{|c|c|c|c|}
\hline Parameters & $\begin{array}{l}\text { GnT-V+ } \\
(\mathrm{n}=23)\end{array}$ & $\begin{array}{r}\text { GnT-V- } \\
(\mathrm{n}=27)\end{array}$ & $\mathrm{p}$ \\
\hline Sex, females/males & 5.18 & 10.17 & $0.24^{\mathrm{a}}$ \\
\hline Size, $\mathrm{cm}$ & $6.4 \pm 2.9^{b}$ & $6.6 \pm 3.6^{\mathrm{b}}$ & $0.41^{\mathrm{c}}$ \\
\hline \multicolumn{4}{|c|}{ Histological differentiation } \\
\hline Well-moderately & 17 & 14 & \multirow[t]{2}{*}{$0.19^{\mathrm{a}}$} \\
\hline Poorly & 6 & 13 & \\
\hline \multicolumn{4}{|l|}{ Lymphatic invasion } \\
\hline Positive & 20 & 24 & \multirow[t]{2}{*}{$0.83^{\mathrm{a}}$} \\
\hline Negative & 3 & 3 & \\
\hline \multicolumn{4}{|l|}{ Venous invasion } \\
\hline Positive & 19 & 16 & \multirow[t]{2}{*}{$0.17^{\mathrm{a}}$} \\
\hline Negative & 4 & 11 & \\
\hline \multicolumn{4}{|c|}{ Lymph node metastases } \\
\hline Positive & 21 & 18 & \multirow[t]{2}{*}{$0.036^{\mathrm{a}}$} \\
\hline Negative & 2 & 9 & \\
\hline \multicolumn{4}{|c|}{ Peritoneal dissemination } \\
\hline Positive & 8 & 1 & \multirow[t]{2}{*}{$0.013^{\mathrm{a}}$} \\
\hline Negative & 15 & 26 & \\
\hline \multicolumn{4}{|l|}{ Liver metastases } \\
\hline Positive & 6 & 1 & \multirow[t]{2}{*}{$0.023^{\mathrm{a}}$} \\
\hline Negative & 17 & 26 & \\
\hline \multicolumn{4}{|l|}{ Curability } \\
\hline $\mathrm{A} / \mathrm{B}$ & 12 & 24 & \multirow[t]{2}{*}{$0.015^{\mathrm{a}}$} \\
\hline $\mathrm{C}$ & 11 & 3 & \\
\hline
\end{tabular}

Curability: $\mathrm{A} / \mathrm{B}=$ no cancer remained; $\mathrm{C}=$ cancer remained (according to the Japanese General Rules for the Gastric Cancer Study in Surgery and Pathology).

${ }^{a} \chi^{2}$ for independence test. ${ }^{b}$ Values are means $\pm S D .{ }^{c}$ Student's t test.

\section{GnT-V Expression and Survival Rate}

We investigated the prognostic value of GnT-V expression in 50 patients of gastric cancer who had undergone surgery. Five-year overall survival for patients with GnTV-negative expression was $54.4 \%$. In contrast, 5-year overall survival for patients with GnT-V-positive expression was only $31.2 \%$ (fig. 2). There was a significant correlation between 5-year survival and GnT-V expression $(\mathrm{p}=0.045)$. Twenty-two patients had pStage I-II gastric cancer: in 2 of 5 patients (40\%) with GnT-V-positive expression survival was $<5$ years compared with only 1 of 17 patients (5.9\%) with GnT-V-negative expression. In the analysis of the relationship between the 5-year survival rate and GnT-V expression, patients with GnT-V-positive gastric cancer had a significantly shorter survival than GnT-V-negative cases (53.3 and 92.9\%, respectively; $\mathrm{p}=$
Table 2. GnT-V expression and pTNM classification of gastric cancer

\begin{tabular}{lccl}
\hline pTNM classification & GnT-V+ & GnT-V - & $p$ \\
\hline Tumor & & & \\
$\quad \mathrm{T}_{2}$ & 13 & 16 & $0.84^{\mathrm{a}}$ \\
$\quad \mathrm{T}_{3} \& \mathrm{~T}_{4}$ & 10 & 11 & \\
Node & & & \\
$\quad \mathrm{N}_{0}$ & 2 & 9 & $0.005^{\mathrm{a}}$ \\
$\mathrm{N}_{1}$ & 11 & 16 & \\
$\mathrm{~N}_{2} \& \mathrm{~N}_{3}$ & 10 & 2 & \\
Metastases & & & \\
$\mathrm{M}_{0}$ & 10 & 24 & $0.002^{\mathrm{a}}$ \\
$\mathrm{M}_{1}$ & 13 & 3 & \\
TNM stage & & & \\
I & 1 & 6 & $0.004^{\mathrm{a}}$ \\
II & 4 & 11 & \\
III & 5 & 7 & \\
IV & 13 & 3 &
\end{tabular}

pTNM stage classification according to the International Union against Cancer; $\mathrm{T}_{2}=$ cancer that invades the muscularis propria or subserosa; $T_{3}=$ cancer that penetrates the serosa without invasion of adjacent structures; $\mathrm{T}_{4}=$ cancer that invades adjacent structures (there is only 1 case); $\mathrm{N}_{0}=$ cancer without lymph node metastasis; $\mathrm{N}_{1}=$ metastasis in $1-6$ regional lymph nodes; $\mathrm{N}_{2}=$ metastasis in 7-15 regional lymph nodes; $\mathrm{N}_{3}=$ metastasis in $>15$ regional lymph nodes (there is only 1 case); $M_{0}=$ cancer without metastasis; $\mathrm{M}_{1}=$ cancer with metastasis.

${ }^{a} \chi^{2}$ for independence.

0.026; fig. 3). For those with pStage III-IV gastric cancer, the survival rate was not significantly different between GnT-V-positive and -negative patients.

\section{Discussion}

In the current study, we demonstrated that GnT-V expression was significantly correlated with a poor prognosis as well as metastases in advanced gastric cancer. Expression of GnT-V was reported to be significantly correlated with a poor prognosis in breast and colorectal cancer [13-15]. It was also mentioned there was a significant association between GnT-V expression and poor prognosis in colon cancer, being mainly attributable to the poor prognosis in pStage II colon cancer [15]. Also, in our study cohort, the survival rate of pStage I-II gastric cancer cases was significantly affected by the expression of GnT-V, while there was no difference between the survival rate and GnT-V expression in pStage III-IV gastric 


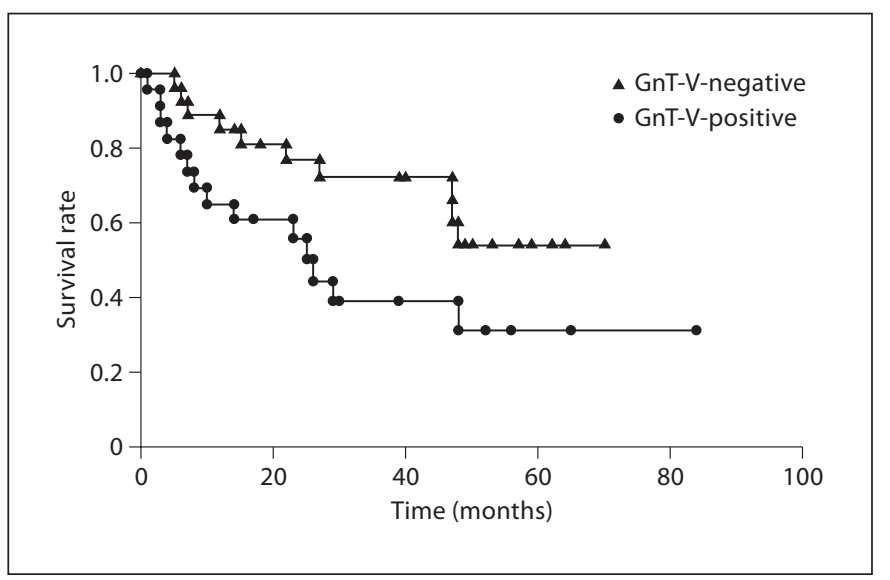

Fig. 2. Overall survival curve of the patients with GnT-V-positive and -negative gastric cancer (Kaplan-Meier plot). Five-year survival rates were 54.4 and $31.2 \%$ for GnT-V-negative and -positive cases, respectively. There was a significant difference in survival between GnT-V-negative and -positive patients $(\mathrm{p}=0.45)$.

cancer. Our result was consistent with a previous report in colorectal cancer. Our immunohistochemical study also showed strong correlation of GnT-V expression with lymph node and distant metastases, including liver metastasis and peritoneal dissemination, and these strong associations appeared to influence a poor prognosis.

GnT-V is a key enzyme in the processing of multiantennary $\mathrm{N}$-glycans during glycoprotein biosyntheses, including cell surface and secreted glycoproteins associated with cancer metastasis. GnT-V, for example, has been known to regulate integrin function through its glycosylation. Cells transfected with the GnT-V gene have been shown to have reduced adhesion to extracellular matrix proteins, such as collagen or fibronectin, and this reduced adhesion has been associated with glycosylation of integrins $\alpha_{5}$ and $\beta_{1}[12,22]$. Increased $\beta_{1-6}$ branched N-glycan on $\beta_{1}$ integrin reduced $\alpha_{5} \beta_{1}$ integrin clustering and stimulated migration of human fibrosarcoma cells in vitro [22]. This phenotype favors the migration of cancer cells in the early steps of metastasis. Furthermore, GnT-V stabilizes and elevates enzymatic activity of a membranetype serine protease, matriptase [19]. Matriptase activates hepatocyte growth factor, and urokinase-type plasminogen activator as well as matriptase can directly degrade extracellular matrix proteins. Since both hepatocyte growth factor and urokinase-type plasminogen activator are involved in cancer invasion, activation of matriptase by GnT-V is also advantageous for the early steps of the

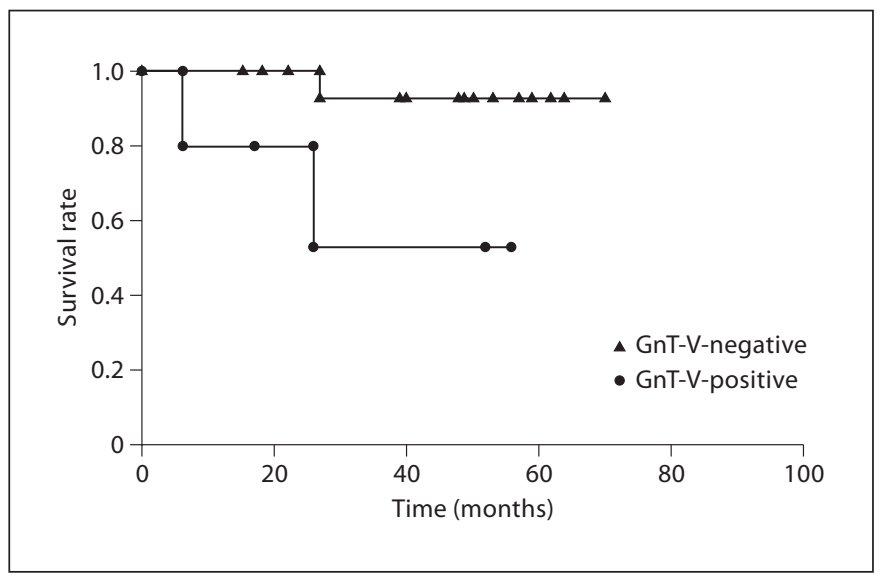

Fig. 3. Overall survival curve of the patients with GnT-V-positive and -negative stage I-II gastric cancer (Kaplan-Meier plot). Fiveyear survival rates were 92.9 and $53.3 \%$ for GnT-V-negative and -positive cases, respectively. There was a significant difference in survival between GnT-V-negative and -positive stage I-II patients $(\mathrm{p}=0.026)$.

metastatic process. On the other hand, GnT-V is involved in the later steps of distant metastases of cancer cells. Sialyl Lewis $\mathrm{X}$ is a ligand for E-selectin, which is attached to the $\mathrm{N}$ - and O-termini of glycans. E-selectin mediates the process by which cancer cells attach to endothelial cells $[23,24]$. In addition, sialyl Lewis $X$ was correlated with metastatic potency in human cancer, including colon cancer, gastric cancer and pancreatic cancer [25-28]. In addition, expression of sialyl Lewis $\mathrm{X}$ was induced by GnT-V expression in colon cancer cells [28]. Moreover, GnT-V itself induced the release of fibroblast growth factor-2 from heparan sulfate proteoglycan, leading to angiogenesis and metastasis in secondary organs [29]. These results suggested that GnT-V influenced the function of various glycoproteins which play important roles in the process of metastasis, and total increased activity of those glycoproteins might induce different types of metastasis: lymph node, peritoneal and liver metastasis.

GnT-V was expressed not only in gastric cancer cells but also in non-cancerous gastric epithelium, including remote gastric mucosa as well as adjacent mucosa. In a previous report, GnT-V was expressed in different normal tissue, including the mouse stomach [30]. $\beta_{1-6} \mathrm{~N}$-glycan synthesized by GnT-V was expressed in epithelial cells of the human stomach [31]. Since immunohistochemical GnT-V expression was apparently lower in normal epithelium, and subcellular localization in normal epithelium is different from that of gastric cancer cells, 
the glycoproteins affected by GnT-V might be different. Previous studies have shown that increases in GnT-V expression after oncogenic transformation are most likely caused by direct effects on the GnT-V promoter by the Ets family of transcriptional activators, which are upregulated by a cellular proliferation signaling pathway [32], supporting our results of increased GnT-V expression in gastric cancer regions compared with normal gastric mucosa. Because the signaling pathway was induced by some growth factors and cytokines, the growth factors and cytokines secreted by cancer cells might influence the expression of GnT-V in non-cancerous tissue surrounding the gastric cancer region. Further investigation will be required for the implication of GnT-V in normal and gastric cancer.

In the current study, GnT-V expression, which was detected by immunohistochemistry, was a valuable factor predicting prognosis after curative resection of gastric cancer. Future advances in diagnostic techniques may facilitate the earlier detection of metastases. Most gastric cancers of pStage I-II are potentially curable by adequate treatment. Identification of specific indicators of invasive or metastatic potential within the primary tumor at the time of surgery (GnT-V expression as shown in the current study) would allow for a better prognostic stratification and more effective treatment of gastric cancer patients. In particular, the stratification of a subset of pStage I-II gastric cancer patients into those with either a favorable or a poor prognosis may be clinically important.

Though treatment of advanced gastric cancer mainly depends on surgical resection, adjuvant therapy has widely been tested in the treatment of gastric cancer. In the USA, the use of postoperative chemoradiation in gastric cancer is considered standard of care now. A significant benefit for overall and disease-free survival was demonstrated for patients with chemoradiotherapy after gastric resection [33]. Recently, decreased $\beta_{1-6}-\mathrm{N}$-acetylglucosamine $\left(\beta_{1-6} \mathrm{GlcNAc}\right)$ branching in $\mathrm{N}$-glycan of $\alpha_{5} \beta_{1}$-integrin was associated with cisplatin resistance in squamous cell cancer [34]. The $\mathrm{N}$-glycan structure of $\alpha_{5} \beta_{1}$-integrin can be changed by down- or upregulation of glycosyltransferases $[12,35]$. Possibly, GnT-V will be used as adjuvant to radiochemotherapy against cisplatinresistant tumor cells, including gastrointestinal cancer.

In conclusion, the biological character of GnT-V critical for the development and prognosis of cancer, and differs among various cancer types, depending on the biological function of the target substrate glycoprotein, which can vary among organs and tissues. In the present study, we demonstrated that GnT-V expression is correlated with distant metastases and a poor prognosis in gastric cancer. The evaluation of the prognosis of postoperative patients of gastric cancer by immunohistochemical assessment of GnT-V may be beneficial regarding future patient management, and GnT-V may also be targeted in the treatment of metastases.

\section{Acknowledgement}

We thank Ms. Kumiyo Hirai for her technical support.

\section{References}

1 Parkin DM, Laara E, Muir CS: Estimates of the worldwide frequency of sixteen major cancers in 1980. Int J Cancer 1988;41:184197.

-2 Hansson LE, Sparen P, Nyren O: Survival in stomach cancer is improving: results of a nationwide population-based Swedish study. Ann Surg 1999;230:162-169.

- 3 Yasui W, Oue N, Ito R, Kuraoka K, Nakayama H: Search for new biomarkers of gastric cancer through serial analysis of gene expression and its clinical implication. Cancer Sci 2004;95:385-392.

4 Becker KF, Keller G, Hoefler H: The use of molecular biology in diagnosis and prognosis of gastric cancer. Surg Oncol 2000;9:511.
5 Shimizu F, Nakayama J, Ishizone S, Zhang MX, Kawakubo M, Ota H, Sugiyama A, Kawasaki S, Fukuda M, Katsuyama T: Usefulness of the real-time reverse transcriptionpolymerase chain reaction assay targeted to $\alpha 1,4-\mathrm{N}$-acetylglucosaminyltransferase for the detection of gastric cancer. Lab Invest 2003;83:187-197.

-6 Hayashi N, Nakamori S, Okami J, Nagano H, Dono K, Umeshita K, Sakon M, Narimatsu $\mathrm{H}$, Monden M: Association between expression levels of CA 19-9 and N-acetylglucosamine- $\beta 1,3$-galactosyltransferase 5 gene in human pancreatic cancer tissue. Pathobiology 2004;71:26-34.
7 Ishikawa M, Kitayama J, Kohno K, Nagawa $\mathrm{H}$ : The expression pattern of UDP-N-acetylalpha-D-galactosamine-polypeptide $\mathrm{N}$-acetyl-galactosaminyl transferase-3 in squamous cell carcinoma of the esophagus. Pathobiology 2005;72:139-145.

-8 Arango J, Pierce M: Comparison of N-acetylglucosaminyltransferase $\mathrm{V}$ activities in Rous sarcoma-transformed baby hamster kidney (RS-BHK) and BHK cells. J Cell Biochem 1988;37:225-231.

-9 Brockhausen I, Narasimhan S, Schachter H: The biosynthesis of highly branched N-glycans: studies on the sequential pathway and functional role of N-acetylglucosaminyltransferases I, II, III, IV, V and VI. Biochimie (Paris) 1988;70:1521-1533. 
10 Ko JH, Miyoshi E, Noda K, Ekuni A, Kang R, Ikeda Y, Taniguchi N: Regulation of the GnT$\mathrm{V}$ promoter by transcription factor Ets-1 in various cancer cell lines. J Biol Chem 1999; 274:22941-22948.

11 Guo HB, Shen ZH, Huang CX, Ma J, Huang Y, Chen HL: Modulation of the basal activity of phosphatidylinositol-3-kinase/protein kinase B signaling pathway in human hepatocarcinoma cells. Glycoconj J 2000;17:315322.

12 Demetriou M, Nabi IR, Coppolino M, Dedhar S, Dennis WJ: Reduced contact-inhibition and substratum adhesion in epithelial cells expressing GlcNAc-transferase V. J Cell Biol 1995;130:383-392.

-13 Fernandes B, Sagman U, Auger M, Demetriou M, Dennis JW: $\beta 1-6$ Branched oligosaccharides as a marker of tumor progression in human breast and colon neoplasia. Cancer Res 1991;51:718-723.

- 14 Seelentag WK, Li WP, Schmitz SF, Metzger U, Aeberhard P, Heitz PU, Roth J: Prognostic value of $\beta 1,6$-branched oligosaccharides in human colorectal carcinoma. Cancer Res 1998;58:5559-5564.

- 15 Murata K, Miyoshi E, Kameyama M, Ishikawa O, Kabuto T, Sasaki Y, Hiratsuka M, Ohigashi $\mathrm{H}$, Ishiguro $\mathrm{S}$, Ito $\mathrm{S}$, Honda $\mathrm{H}$, Takemura F, Taniguchi N, Imaoka S: Expression of $\mathrm{N}$-acetylglucosaminyltransferase $\mathrm{V}$ in colorectal cancer correlates with metastasis and poor prognosis. Clin Cancer Res 2000;6:1772-1777.

16 Ito Y, Miyoshi E, Sakon M, Takeda T, Noda $\mathrm{K}$, Tsujimoto $\mathrm{M}$, Ito $\mathrm{S}$, Honda $\mathrm{H}$, Takemura F, Wakasa K, Monden M, Matsuura N, Taniguchi N: Elevated expression of UDP-Nacetylglucosamine: $\alpha$-mannoside $\beta 1,6 \mathrm{~N}$ acetylglucosaminyltransferase is an early event in hepatocarcinogenesis. Int J Cancer 2001;91:631-637.

-17 Dosaka-Akita H, Miyoshi E, Suzuki O, Itoh $\mathrm{T}$, Katoh $\mathrm{H}$, Taniguchi N: Expression of Nacetylglucosaminyltransferase $\mathrm{V}$ is associated with prognosis and histology in nonsmall cell lung cancer. Clin Cancer Res 2004; 10:1773-1779.
18 Taniguchi N, Ihara S, Saito T, Miyoshi E, Ikeda Y, Honke K: Implication of GnT-V in cancer metastasis: a glycomic approach for identification of a target protein and its unique function as an angiogenic cofactor. Glyoconj J 2001;18:859-865.

19 Ihara S, Miyoshi E, Ko JH, Murata K, Nakahara S, Honke K, Dickson RB, Lin CY, Taniguchi N: Prometastatic effect of N-acetylglucosaminyltransferase $\mathrm{V}$ is due to modification and stabilization of active matriptase by adding $\beta 1-6$ GlcNAc branching. J Biol Chem 2002;277:16960-16967.

20 Pasini F: The new TNM classification of lymph node metastasis minimises stage migration problems in gastric cancer patients. Br J Cancer 2002;87:171-174.

21 Livingstone JI, Yasui W, Tahara E, Wastell C: Are Japanese and European gastric cancer the same biological entity? An immunohistochemical study. Br J Cancer 1995;72:976980.

22 Guo HB, Lee I, Kamar M, Akiyama SK, Pierce M: Aberrant N-glycosylation of $\beta_{1}$ integrin causes reduced $\alpha_{5} \beta_{1}$ integrin clustering and stimulates cell migration. Cancer Res 2002;62:6837-6845.

23 Schachter H: Biosynthetic controls that determine the branching and microheterogeneity of protein-bound oligosaccharides. Adv Exp Med Biol 1986;205:53-85.

24 Phillips ML, Nudelman E, Gaeta FC, Perez M, Singhal AK, Hakomori S, Paulson JC: ELAM-1 mediates cell adhesion by recognition of a carbohydrate ligand, sialyl-Lex. Science 1990;250:1130-1132.

25 Matsushita Y, Cleary KR, Ota DM, Hoff SD, Irimura T: Sialyl-dimeric Lewis-X antigen expressed on mucin-like glycoproteins in colorectal cancer metastases. Lab Invest 1990;63:780-791.

26 Nakamori S, Kameyama M, Imaoka S, Furukawa H, Ishikawa O, Sasaki Y, Izumi Y, Irimura T: Involvement of carbohydrate antigen sialyl Lewis(x) in colorectal cancer metastasis. Dis Colon Rectum 1997;40:420 431.

-27 Takahashi S, Oda T, Hasebe T, Sasaki S, Kinoshita T, Konishi M, Ueda T, Nakahashi C, Ochiai T, Ochiai A: Overexpression of sialyl Lewis $\mathrm{x}$ antigen is associated with formation of extratumoral venous invasion and predicts postoperative development of massive hepatic metastasis in cases with pancreatic ductal adenocarcinoma. Pathobiology 2001;69:127-135.
28 Kannagi R: Carbohydrate-mediated cell adhesion involved in hematogenous metastasis of cancer. Glycoconj J 1997;14:577-584.

29 Saito T, Miyoshi E, Sasai K, Nakano N, Eguchi H, Honke K, Taniguchi N: A secreted type of beta 1,6-N-acetylglucosaminyltransferase $\mathrm{V}(\mathrm{GnT}-\mathrm{V})$ induces tumor angiogenesis without mediation of glycosylation: a novel function of GnT-V distinct from the original glycosyltransferase activity. J Biol Chem 2002;277:17002-17008.

30 Perng GS, Shoreibah M, Margitich I, Pierce $\mathrm{M}$, Fregien N: Expression of N-acetylglucosaminyltransferase $\mathrm{V}$ mRNA in mammalian tissues and cell lines. Glycobiology 1994;4: 867-871.

31 Li WP, Roth J: Expression of $\beta 1,6$ branched asparagine-linked oligosaccharides in nonmitotic and non-migratory cells of normal human and rat tissues. Int J Cancer 1997;71: 483-490.

- 32 Pierce M, Buckhaults P, Chen L, Fregien N: Regulation of $\mathrm{N}$-acetylglucosaminyltransferase $\mathrm{V}$ and Asn-linked oligosaccharide $\beta(1,6)$ branching by a growth factor signaling pathway and effects on cell adhesion and metastatic potential. Glycoconj J 1997;14: 623-630.

33 Macdonald JS: Clinical overview: adjuvant therapy of gastrointestinal cancer (review). Cancer Chemother Pharmacol 2004;54 (suppl 1):S4-S11.

- 34 Nakahara S, Miyoshi E, Noda K, Ihara S, Jianguo G, Honke K: Involvement of oligosaccharide changes in $\alpha_{5} \beta_{1}$ integrin in a cisplatin-resistant human squamous cell carcinoma cell line. Mol Cancer Ther 2003;2: 1207-1214.

35 Miyoshi E, Noda K, Ko JH, Ekuni A, Kitada T, Uozumi N, Ikeda Y, Matsuura N, Sasaki Y, Hayashi N, Hori M, Taniguchi N: Overexpression of 1-6 fucosyltransferase in hepatoma cells suppresses intrahepatic metastasis after splenic injection in athymic mice. Cancer Res 1999;59:2237-2243. 